\title{
O SISTEMA DE INFORMAÇÕES NO PROCESSO GERENCIAL DOS SERVIÇOS DE SAÚDE: ALGUMAS REFLEXÕES *
}

\author{
Silvana Martins Mishima ** \\ Tereza Cristina Scatena Villa ** \\ Elizaheth Laus Ribas Gomes *** \\ Maria Tereza Romão Pratali ${ }^{\star \star \star *}$ \\ Eliete Maria Silva ** \\ Maria Luiza Anselmi***
}

MISHIMA, S. M.; VILLA, T. C. S.; GOMES, E. L. R.; PRATALI, M. T. R.; SILVA, E. M. ANSELMI, M. L. O sistema de informações no processo gerencial dos serviços de saúde: algumas reflexões. Rev.latino-am.enfermagem, Ribeirão Preto, v. 4, na especial, p. 83-9, abril 1996.

Neste ensaio nos dispomos a desenvolver algumas reflexões acerca da constituição do sistema de informação como um dos principais instrumentos. para o gerenciamento de serviços de saúde. no processo de municipalização.

UNITERMOS: municipalização, sistema de informação, processo gerencial

* Este trabalho foi produzido por membros do Grupo de Trabalho e Pesquisa Gerenciamento/Informática, grupo interdisciplinar com a participação da Escola de Enfermagem de Ribeirão Preto da Universidade de São Paulo e Secretaria Municipal de Saúde de Ribeirão Preto

** Docentes do Departamento de Enfermagem Materno-Intantil e Saúde Pública da Escola de Enfermagem de Ribeirão Preto da Universidade de São Paulo

*** Docentes do Departamento de Enfermagem Geral e Especializada da Escola de Enfermagem de Ribeirão Preto da Universidade de São Paulo.

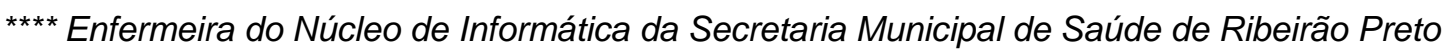




\section{I - INTRODUÇÃO}

As reflexões aqui desenvolvidas abordarão o sistema de informações dos serviços de saúde, enquanto um instrumento do processo gerencial em saúde.

A partir da concepção de distritos sanitários, procuramos desenvolver uma análise dos avanços e limites, hoje presentes, na organização dos serviços de saúde e localizar o sistema de informação como um instrumento que possibilita o desenvolvimento de várias ações coordenadas e compreende, principalmente o intercâmbio de informações e idéias necessárias à tomada de decisões.

Desenvolver esta reflexão por referência à constituição do Sistema Único de Saúde - SUS, nos remete à necessidade de discutirmos algumas questões fundamentais ao entendimento deste processo e em seguida arriscar algumas considerações acerca da instituição de um sistema de informações que possa ser elemento fundamental para a consolidação do Sistema Único de Saúde - SUS.

\section{II - ORGANIZAÇÃO DOS SERVIÇOS DE SAÚDE NO PROCESSO DA MUNICIPALIZAÇÃO}

A proposta de municipalização, presente já na década de 60 , foi objeto de debate na III Conferência Nacional de Saúde em 1963, contudo, começou a ganhar corpo efetivamente no interior do movimento da Reforma Sanitária e na VIII Conferência Nacional de Saúde, realizada em 1986.

Foi neste momento, em que se deliberou pela reorientação do sistema de saúde, baseando-se nos princípios de descentralização e do fortalecimento dos níveis periféricos, através de uma maior autonomia na tomada de decisões em relação à própria prestação de serviços ${ }^{1: 211}$, que abriu-se caminho para propostas de reorganização dos serviços calcadas nos pressupostos da descentralização, autonomia local e participação da sociedade.

O processo de municipalização da saúde, como estratégia de consolidação do SUS, pressupõe o fortalecimento do poder local (do ponto de vista institucional e financeiro) de forma que a instância municipal tenha autonomia para gestão da política de saúde adotada.

Entendemos que a municipalização dos serviços de saúde é parte de um processo de descentralização política, técnica e administrativa do sistema de saúde, onde novas relações passam a ser estabelecidas entre o nível central e o nível local. Estas traduzem-se na formulação e implementação de políticas, organização e gestão dos processos de trabalho e manejo de recursos (financeiros, humanos, fiscais e materiais).

Ao se falar em processo de descentralização política, técnica e administrativa, refere-se, respectivamente, à capacidade de mobilizar vontades; ao 
manejo de informações, conhecimentos e tecnologia e ao manejo de recursos no sentido mais tradicional, ou seja, recursos físicos, financeiros, humanos e materiais ${ }^{2}$.

A municipalização não pode significar apenas a transferência de unidades e serviços para os municípios. Essa transferência deve ser acompanhada dos recursos correspondentes que permitam seu pleno e adequado funcionamento. A municipalização ultrapassa, no entanto, o simples repasse direto de recursos, implicando na gestão efetiva e no controle social, devendo ser um instrumento de democratização, garantindo-se o controle social do processo como estratégia fundamental para impulsionar toda a descentralização ${ }^{3: 20}$.

É possível constatar nos últimos cinco anos, no Estado de São Paulo, uma expansão da rede pública e uma correspondente ampliação da oferta de serviços de saúde, particularmente na área do atendimento básico, bem como a expansão e alteração do perfil de recursos humanos atuantes no setor ${ }^{4,5}$.

Reconhecemos que o processo de municipalização vem representando um avanço na organização dos serviços de saúde, contudo, é preciso admitir que existe uma série de evidências indicativas de problemas e dificuldades nesse processo de descentralização.

\section{II.1 - Os limites do processo de descentralização de serviços de saúde}

Algumas das barreiras com as quais temos nos defrontado dizem respeito às dificuldades de: unificar e democratizar as instituições públicas de saúde; solucionar a questão do financiamento do sistema; articular propostas viáveis para áreas como as de medicamentos, tecnologia e equipamentos, recursos humanos, entre outras, cujas soluções encontram-se fora do âmbito exclusivo do município; superar o atual modelo médico assistencial; assegurar o direito à saúde a todos os cidadãos, bem como, garantir o efetivo controle social do sistema.

Tais barreiras localizadas no interior do setor e fora dele, têm levado a resultados bastante desfavoráveis ao nível dos serviços, que podem ser traduzidos pela ociosidade e inoperância das ações e dos serviços públicos, e ainda a degradação de equipamentos, instalações e salários ${ }^{6}$.

Hoje, o que pode ser observado em grande parte dos municípios brasileiros é a transformação dos mesmos em meros prestadores de serviços de saúde ${ }^{7}$, sendo que na prática não há a transferência de gestão, e ao mesmo tempo predomina a manutenção do modelo clínico de atenção médica, aos moldes do antigo Instituto Nacional de Assistência Médica e Previdência Social - INAMPS.

\section{II.2 - A concepção de Distritos de saúde e o componente gerencial}

Vivenciamos um processo onde avanços e retrocessos se fazem presentes, sendo necessária a avaliação permanente do jogo de forças atuantes de forma a se garantir a viabilidade de transformações.

O distrito sanitário é entendido como a estrutura descentralizada da 
administração municipal. O Distrito sanitário é a unidade operacional e administrativa mínima do Sistema de saúde, definida com critérios territoriais, populacionais, epidemiológicos, administrativos e políticos, onde se localizam recursos de saúde públicos e privados, organizados através de um conjunto de mecanismos político-institucionais, que incluem a participação da sociedade, para desenvolver ações integrais de saúde capazes de resolver a maior quantidade possível de problemas de saúde [...] 7:58

Atualmente, no concreto da organização dos serviços de saúde, o distrito sanitário tem-se reduzido a uma divisão territorial da cidade, com uma instância administrativa correspondente. Levando-se em conta este limite, e tendo-se a perspectiva de viabilizar uma proposta que possa ir se conformando neste espaço de lutas políticas, consideramos que se faz necessário a discussão de alguns pontos que, aqui, pelo nosso interesse mais imediato, chamaremos de questões de ordem gerencial.

Com a possibilidade de aprofundamento da proposta de descentralização, consideramos que algumas atividades de caráter gerencial são fundamentais para a consolidação dos distritos de saúde e o fortalecimento da rede básica de saúde, de forma que esta possa se constituir efetivamente na porta de entrada a um sistema de saúde hierarquizado, regionalizado, e tendo como princípios a integralidade das ações de saúde e onde o controle social possa ser exercido.

Consideramos corno algumas das atividades essenciais para a consolidação dos distritos de saúde ações de: coordenação das unidades próprias e das atividades intersetoriais voltadas para a saúde; diagnóstico e análise da situação de saúde; definição de estratégias necessárias para a superação dos problemas de saúde; organização das equipes de saúde; gerência de material de consumo e de pessoal; coordenação de atividades de manutenção e recuperação de equipamentos e áreas físicas, coordenação e avaliação do fluxo de referência e contra-referência entre os níveis de atenção.

Para tal operacionalização se faz necessária. ainda a consolidação de alguns aspectos e entre eles a implantação de um sistema de informações que contemple todos os níveis de atenção, um sistema de informações que permita aos gestores, aos trabalhadores de saúde e a população conhecer com atualidade e profundidade as matérias sobre as quais devem decidir ${ }^{7: 59}$.

III - ALGUMAS CONSIDERAÇÕES SOBRE O SISTEMA DE INFORMAÇÕES EM SAÚDE ENQUANTO ELEMENTO DO PROCESSO GERENCIAL NA PERSPECTIVA DA CONSTRUÇÃO DOS DISTRITOS DE SAÚDE

O sistema de informação compreendido enquanto um instrumento flexível e dinâmico que dá suporte e fortalece o processo de gerenciamento (no que diz 
respeito ao uso de informações para planejar, acompanhar e avaliar atividades), subsidiando a tomada de decisão, em sua dinâmica interna, deve contemplar as diretrizes básicas que dão sustentação ao modelo assistencial no município.

Isto significa que não existem padrões fixos para a construção de sistemas de informação, bem como de instrumentos de coleta de informações, mas que os mesmos deverão ser construídos de acordo com os parâmetros fixados dentro da proposta política de organização dos serviços do município. Ou seja, há necessidade de se dispor de sistemas flexíveis capazes de se adaptarem às diferentes realidades ${ }^{8}$.

Hoje, o que se observa e que as informações contlnuam centrallzadas, a nível regional estadual (Escritórios Regionais de Saúde - ERSAS, no caso daqueles municípios que ainda não dispõem de condições para sistematizar as informações produzidas localmente) ou em nível do município, sendo que a análise e agregação, dos dados não são submetidas a um processo de sistematização e de discussão nos diferentes níveis do sistema (distrital e local) de forma que possam subsidiar a proposição de ações a serem desenvolvidas, bem como correções nos rumos do trabalho atualmente empreendido.

Ou seja, a discussão não tem chegado aos produtores destas informações, às Unidades Básicas de Saúde e às Unidades Básicas e Distritais de Saúde, de forma a se constituírem em dados a serem trabalhados.

A correção desta distorção parece fundamental para se considerar os "dados vivos", ou seja, a possibilidade de retorno das informações, devidamente consolidados ao nível local que gerou os dados primários, é necessária para dar sentido às informações coletadas e se tornar (quando devidamente trabalhadas), estímulo a um processo de envolvimento e compromisso das equipes com a 'qualidade do trabalho.

Ao lado dessa questão, tem-se, atualmente, que o registro de dados está, baseado nas informações solicitadas pelos órgãos estadual/federal, para efeito de faturamento e pagamento, ou seja, do financiamento do sistema de saúde, sendo que ainda são raras as experiências das secretarias de saúde que conseguiram avançar um pouco, ampliando os seus registros de acordo com as necessidades dinâmicas e específicas, da clientela e do município ${ }^{9}$.

Portanto, as informações e a periodicidade estão estruturadas de acordo com o que é solicitado pelos níveis centrais, sem discussão sobre os instrumentos reais necessários para cada localidade, prevalecendo os registros de produção médica, procedimentos de enfermagem, vacinação, etc, uma vez que atendem a uma necessidade precípua de financiamento, ou seja, o município é visto e assume o papel de mero prestador de serviços, e o sistema de 'informações serve como sistematizador e quantificador da produtividade dos serviços. Por outro lado, a nível central o repasse dos dados agregados é deficitário, para que os mesmos possam, mesmo que quantitativamente, servir como indicador da organização dos servlços a nível local ${ }^{10}$.

São necessárias, portanto, informações relativas, não apenas à produção dos serviços de saúde, mas também aos dados demográficos de regiões específicas (e não de grandes aglomerados populacionais, identificando fluxos migratórios e 
características específicas da população); à morbidade e mortalidade, não apenas da demanda espontânea ao serviços (uma vez que estes dados podem apresentar distorções, por não captarem a demanda reprimida aos serviços) de forma a se dispor de um perfil de saúde da população da área adstrita; aos recursos institucionais e extra-institucionais da área de abrangência, condições ambientais e de saneamento (água, lixo, esgoto, poluição ambiental).

Outros dados podem ser acrescidos a estes, sempre que necessários ao processo de gerenciamento, sendo fundamental ressaltar que o sistema de informação só adquire sentido na medida em que os dados "acumulados" sejam trabalhados ao nível local efetivando-se a possibilidade de construção de alternativas de intervenção dentro das diferentes realidades de saúde que se colocam no espaço dos municípios.

As questões que aqui colocamos para reflexão não esgotam a amplitude e a complexidade da temática, mas certamente têm estado presentes em nosso universo de discussão e prática diuturna na área da saúde, Finalizando, gostaríamos de trazer uma citação de DE KADT citado por TASCA et al (1994), que retrata o teor de nossas reflexões: um sistema de informações em saúde serve às necessidades de quem o usa. Informação é poder apenas na medida em que é potencialmente sustentadora de ação [... $]^{9}$.

\section{INFORMATION SYSTEM IN THE MANAGEMENT PROCESS OF HEALTH SERVICES: SOME REFLECTIONS}

The present study aims at reflecting about the organization of the information system as an important tool in the management of health services, especially in, the process of municipalization.

UNITERMS: municipalization, system of information, management process

\section{EL SISTEMA DE INFORMACIONES EN EL PROCESO GERENCIAL DE LOS SERVICIOS DE SALUD: ALGUNAS REFLEXIONES}

En este estudio las autoras desarrollan algunas reflexiones a cerca de la constitución del sistema de información como un de los principales instrumentos para el gerenciamento de los servicios de salud, en el proceso de municipalización.

UNITERMOS: municipalización, sistema de información, proceso gerencial 


\section{REFERÊNCIAS BIBLIOGRÁFICAS}

01. GAWRYSZEWSKI, V. Reorganização dos serviços de saúde: algumas considerações acerca da relação entre a descentralização, autonomia local e a participação do cidadão. Cad.Saúde Pública, Rio de Janeiro, v. 9, n. 2, p. 21015,1993.

02. TEIXEIRA, C. F. A municipalização da saúde: os caminhos do labirinto. Saúde Debate, n. 33, p. 27-32, 1991.

03. BRASIL. Universidade de Brasília. Municipalização é o caminho. In: CONFERENCIA NACIONAL DE SAÚDE, 9, Brasília, 9 a 14 de agosto de 1992. Relatório. Brasília, UnB, 1992, p. 46 (mimeografado).

04. TANAKA, O. Y .et al. A municipalização dos serviços de saúde no Estado de São Paulo. Saúde Debate, n. 33, p. 73-70, 1991.

05. PIMENTA, M. A. L. O SUS e a municipalização à luz da experiência concreta. Saúde Soc., v. 2, n. 1, p. 25-40, 1993.

06. CAMPOS, G.W de S. Um balanço do processo de municipalização dos serviços de saúde no Brasil. Saúde Debate, n. 28, p. 24-8, 1990.

07. MISOCZKY, M.C. Distrito sanitário: desafio de descentralizar com democracia. Saúde Debate, n. 33, p. 54-60, 1991.

08. DONALíSIO, M.R. A informação e o município. Saúde Debate, n. 39, p. 64-9,1993.

09. TASCA, R.; GRECO, C.; NOTARBARTOLO DIV., F. Sistemas de informação em saúde para distritos sanitários. In: MENDES, E. V. (org) Distrito sanitário. 0 processo social de mudança das práticas sanitárias do Sistema Único de Saúde. 2. ed. São Paulo: HUCITEC-ABRASCO, 1994. Cap.7, p. 267-310.

10. SIMÕES, B. J. G.; FORSTER, A. C.; YAZLLE ROCHA, J. S. Informações em saúde para o SUS II. Sistemas hospitalar e ambulatorial. Medicina, v. 26, n. 3, p. 423-29, 1993. 